DRAKE, M.A., KARAGUL-YUCEER, Y., CADWALLADER, K.R., CIVILLE, G.V. and TONG, P.S. (2003), DETERMINATION OF THE SENSORY ATTRIBUTES OF DRIED MILK POWDERS AND DAIRY INGREDIENTS. Journal of Sensory Studies, 18: 199-216. doi: 10.1111/j.1745-459X.2003.tb00385.x

\title{
DETERMINATION OF THE SENSORY ATTRIBUTES OF DRIED MILK POWDERS
}

\section{AND DAIRY INGREDIENTS}

\author{
M.A. DRAKE ${ }^{1}$, Y. KARAGUL-YUCEER ${ }^{1}$, K.R. CADWALLADER ${ }^{2}$, G.V. CIVILLE $^{3}$ and P.S. \\ $\mathrm{TONG}^{4}$ \\ ${ }^{1}$ Dept. Food Science, Box 7624 \\ Southeast Dairy Foods Research \\ Center \\ North Carolina State University \\ Raleigh, NC 27695 \\ ${ }^{2}$ Dept. Food Science and Human \\ Nutrition \\ University of Illinois \\ Urbana-Champaign, IL 61801 \\ ${ }^{3}$ Sensory Spectrum, Inc. \\ 24 Washington Ave. \\ Chatham, NJ 07928 \\ ${ }^{4}$ Dairy Products Technology \\ Center \\ California Polytechnic \\ University \\ San Luis Obispo, CA 93407
}

\begin{abstract}
A standardized descriptive language for skim milk powder and dried dairy ingredients was developed. The lexicon was initially identified from a large sample set of dried dairy ingredients (138). A highly trained descriptive panel $(n=14)$ refined terms and identified references. Dried dairy ingredients (36) were then evaluated using the developed language. Twenty-one descriptors were identified for dried dairy ingredients. Seventeen flavors and tastes were identified in skim milk powders (27) with nine flavors/tastes observed in all skim milk powders. Dried dairy ingredients were differentiated using the language (P C 0.05). There were flavors common to all dried dairy ingredients while other flavors were specific to particular products.
\end{abstract}

\section{INTRODUCTION}

Worldwide very large amounts of dried milk products are manufactured. The primary dry milk product manufactured in the U.S. is skim milk powder (SMP) although whole milk powder is also produced (ADPI 2000). Over 663,000 tons of SMP and over 50,000 tons of whole milk powder (WMP) were produced domestically in 2000 (ADP! 2000). SMP is mainly produced by spray-drying of fluid pasteurized milk and the finished product composition is not more than 1.5\% fat by wt (ADPI 1998), Three basic types of SMP are produced: low heat, medium heat, and high heat (ADPI 1998). Typically, SMP should have a shelf-life (at 25C) of 12-18 months 
(ADPI 1998). Currently, U.S. SMP production continues to increase while the U.S. has only a 17\% share of the world SMP market (Lagrange 2001). The global market for SMP is expected to grow by $20 \%$ by the year 2005 (Lagrange 1998).

SMP and other dried dairy ingredients should ideally have a clean, sweet and pleasant taste free of flavor defects (Bodyfelt er a!, 1988). For SMP, cooked flavors may be present and vary according to heat treatment (low, medium, high) of the milk prior to evaporation and spray-drying. Dry milk products must have good flavor characteristics for direct consumption as well as for product applications. The largest outlet for SMP is ingredient application in dairy products. Recommended applications of SMP classification based on preheat treatment vary. Low and medium heat-treated powders are used in fluid milk fortification, cottage cheese, yogurt and chocolate dairy drinks because of their high solubility and minimal cooked flavor. However, high heat powders are mostly used in bakery, confectionery, meat products for texture modification, water absorption/binding, emulsification and gelation (Varnam and Sutherland 1996; ADPI 1998). Off-flavors present in SMP and other dried dairy ingredients can carry through to the final end-product and result in poor end-product quality. Therefore, flavor and sensory properties are considered important criteria in grading dry milk powders and other dried dairy ingredients (Bodyfelt et al. 1988).

Grading has been used by the industry for many years to evaluate overall quality of milk powders and other dried dairy ingredients but is defect-based, rather than descriptive in nature. These defects are not well-defined, and grades are based on one person's somewhat subjective opinion. Descriptive sensory analysis is traditionally used to identify and quantify flavors in products and can be a powerful tool for describing and differentiating product flavors for research, product development or marketing (Meilgaard et al. 1999; Drake and Civille 2003). 
Previous research that has addressed flavor of SMP has not used descriptive sensory analysis (Kurtz et al. 1971; Driscoll et al. 1985). Descriptive sensory analysis has been conducted widely on fluid milk (Lawless and Claassen 1993; Watson and McEwan 1995; Chapman et al. 2001; Born Frost et al. 2001), as well as ice cream (Prindiville et al. 1999, 2000) and defined sensory languages have been developed specifically for cheese (Heisserer and Chambers 1993; Murray and Delahunty 2000; Drake er al. 2001). Descriptive sensory flavor research has not been conducted on milk powders or other dried dairy ingredients. Since flavor consistency has reportedly been a problem in SMP and WMP (Dryer 1999), the development of a descriptive sensory language for SMP and WMP would provide a powerful research and quality control tool. The objective of this study was to identify and develop a descriptive sensory language for milk powders and other dried dairy ingredients.

\section{MATERIALS AND METHODS}

\section{Milk Powders and Dried Dairy Ingredients}

SMP, WMP and other dried dairy ingredients were donated or purchased from producers nationally and internationally. Thirty eight SMP were obtained from U.S. producers (twenty low heat, five medium heat, thirteen high heat) and twenty-four SMP were obtained from international sources in eleven countries (seventeen low heat, four medium heat, three high heat). An additional fourteen SMP (all low heat) were obtained from U.S. universities that varied in age from 3 months to 20 years. Eleven WMP (eight U.S., three international) were obtained. Sixteen whey protein concentrates (WPC) or whey protein isolates (WP1), five milk protein concentrates (MPC), and ten caseinates were also obtained from U.S. and international producers. The other dairy ingredients were obtained to get as wide an array of dairy milk 
product flavors as possible. Samples were received as 1, 5.10 or $50 \mathrm{lb}$ samples and were stored at -20C in the dark upon receipt. For sensory analysis, skim milk powders were rehydrated on a $10 \%$ solids basis, $10 \mathrm{~g}$ SMP/100 mL water (ADPI 2001) and whole milk powders were rehydrated using the formula: 1000/100-dry \%fat content of WMP = g of WMP dissolved in $90 \mathrm{~g}$ water (IDF 1997). Powders were rehydrated on the percent solids basis with deodorized water (prepared by boiling $4 \mathrm{~L}$ of distilled water until its volume was decreased by one-third) and blended with an electric hand-held mixer. Eight percent-solution of WPC, WPIs, MPCs and caseinates were rehydrated in warm water (60C) based on their protein amount (Harris 2000).

\section{Language Identification and Development}

Rehydrated powders were evaluated for flavor and initial language generation by a group of six individuals experienced ( $>500 \mathrm{~h}$ experience each) with descriptive analysis of products. Rehydrated powders were dispensed into Styrofoam cups with lids (to prevent light oxidation) and allowed to equilibrate to $7 \mathrm{C}$ for $1 \mathrm{~h}$ prior to evaluation. The initial language is listed in Table 1. The panel also grouped the rehydrated powders based on general flavors for future evaluation and language refinement. [Table 1]

\section{Fine-tuning and Identification of References}

Following the roundtable and generation of the preliminary language, a descriptive panel was trained to refine the developed language and to identify references. Fourteen individuals, six male and eight female, 22 to 44 years of age were selected from university staff and students based on availability, interest, and a demonstrated liking of dairy products, including milk. Twelve panelists had prior experience with descriptive analysis. The panel received fifty 
hours of training using the Spectrum' method (Meilgaard et al. 1999) and the identified language. The rehydrated dairy ingredients initially evaluated and grouped were presented to the panel. Panelists were encouraged to volunteer new descriptive terms and to address existing terms. Panelists received food treats and monthly gift certificates at local restaurants for their participation. During training, panelists were presented with and evaluated potential references (food or chemical) and the panelists selected the best reference(s) to represent the identified descriptive terms [Table 2].

\section{Sample Evaluation}

To evaluate the efficacy of the identified language, thirty six samples were selected for examination (Table 3). Some of these products were from the initial sample set used to generate the language, others were newly obtained. The sample set focused on SMP since this was our primary goal. Panelists evaluated each sample in quadruplicate across forty tasting sessions across a 10-week period. Three samples were evaluated per session; samples were presented in a randomized balanced block design within each session. A completely randomized design was used to select samples for each session.

Rehydrated powders were dispensed into Styrofoam cups with lids (to prevent light oxidation) and three digit codes and allowed to equilibrate to $7 \mathrm{C}$ for $1 \mathrm{~h}$ prior to evaluation. Panelists were presented with a warm-up sample of fluid skim milk and then began sample evaluation. Panelists evaluated the samples using the developed language with a 15-point numerical SpectrumTM scale on paper ballots. Bottled water was provided to cleanse the palate during evaluation.

\section{Statistical Analysis}


Significance was established at $\boldsymbol{P}<0.05$. Statistical analysis was conducted using SAS (version 8.0. Cary, NC). Analysis of variance with means separation (PROC GLM) was conducted to evaluate panel consistency across replication of the same sample and to determine significant differences between samples for each attribute. Principal component analysis (PROC PRINCOMP) and factor analysis (PROC FACTOR) were conducted to determine how the SMP were differentiated and to identify redundant terms. Correlation analysis (PROC CORR) with Bonferroni's adjustment was also conducted to determine individual relationships between terms.

\section{RESULTS AND DISCUSSION}

Group discussion and evaluation of SMP and other dried dairy ingredients was conducted for each term in the lexicon following initial language identification. The refined language is listed in Table 2. During language refinement, panelists were able to separate several terms that originally were confounded. Caramelized/sweet aromatic/vanillin were originally grouped together, but were separated into caramelized/butterscotch and sweet aromatic/cake mix by subsequent panel discussion and agreement. Animal-type flavors were also separated into animal/banly and animal/wet dog as were fried fattylpainty and fishy. [Table 3]

Definitions and references were also identified for each descriptor (Table 2). In some cases multiple references were identified. The use of more than one reference for a descriptor can help panelists with different perceptions and experiences of a descriptor focus on the particular concept of interest (Civille and Lawless 1986; Ishii and $\square$ 'Mahoney 1991; Drake and Civille 2003).

Chemical references were also identified when possible. Since not all food types are available world-wide, chemical references allow for clarification of flavor lexicons for future use, and/or comparison. In some cases, chemical sources of particular flavors have not been 
identified and certainly are an area where future research is warranted. Karagul-Yuceer et al. (2001, 2002a) determined aroma-active components of SMP with different sensory properties. They hypothesized that some sensory flavors in SMP were caused by a mixture of two or more chemicals which complicates identification of single chemical references. The term cereal/grassy was one example where chemical references may help clarify concepts. Panelists agreed that this term could potentially be separated into two terms, cereal (dried grain) and grassy (fresh grain, grass) but had trouble consistently differentiating the two flavors in samples. The identification of specific chemical anchors may help further subdivide the term in future studies.

Skim milk powders were differentiated using the lexicon (Table 4, Fig. 1, 2). Panelist performance was consistent as evidenced by the consistently small LSD in univariate analysis (Table 4). There was not a replicate effect across the four replications further indicating consistent panel performance (P7 0.05). Nine descriptors were found in all 27 SMP (Table 4) evaluated while a few terms were found in one or two SMP (Table 5). Of the SMP in Table 5, both SMP 14 and 18 were clearly unusual. SMP 14 was 20 years old and not surprisingly exhibited flavor properties and intensities not observed commonly in SMP. SMP 18 was 3 years old and had been stored at extreme temperatures (35C). Again, it should not be surprising that unusual flavors would be observed in this SMP. SMP 23 was a high heat SMP that was suspected by the company that provided it as being "scorched". The presence of burnt flavor and bitter taste was not surprising given this information. Clearly, some flavors are only occasionally observed in SMP while others are more common. A lexicon with flavors that are commonly observed and additional flavors that are observed less often has also been noted with other foods including Cheddar cheese (Drake et al. 2001) and sourdough bread (Lotong et al. 
2000). Such a lexicon provides a platform to use a smaller number of terms when only a few SMP are evaluated.

Principal components analysis indicated that four principal components (PC's) had Eigenvalues greater than 1 and explained 82\% of the variance (Fig. 1, 2, Table 7). PC1 was comprised of the descriptors sweet aromatic with animal/wet dog and potato/brothy inversely associated. Sweet aromatic and animal/wet dog and potato/brothy were also inversely correlated (Table 8). The aromatics animal/wet dog and potato/brothy are likely to overpower the delicate flavor sweet aromatic, hence their inverse correlation. PC2 was comprised of cooked/sulfur with cereal/grass-like and salty inversely associated. PC3 was primarily the chemical feeling factor astringency and PC4 was sweet taste and cardboard inversely associated. Other trends observed by principal components were also confirmed by fluid skim milk including cooked, sweet aromatic, and sweet taste were correlated while flavors not associated with fluid milk such as animal/wet dog, potato/brothy were also correlated with each other. SMP were loosely grouped into three categories upon visual observation of biplots of PC I and 2 (Fig. 1, 2). A group of SMP were characterized by sweet aromatic, sweet taste, and cooked, a group of SMP were characterized by animal/wet dog and potato/brothy flavors and astringency, and a few SMP were characterized by cereal/grassy and cardboard flavors. Ideally, SMP should have flavors similar to fluid skim milk. Results in Fig. 1 suggest that this idea] is possible since a group of SMP were associated in the same sample space as fluid skim milk. At the same time, a large number of SMP, many less than 3 months in age, exhibited flavors unlike fluid skim milk (potato/brothy, animal/wet dog, astringent). The standard shelf-life for ingredient application of SMP is 18 months at 21C (ADP! 1998). Clearly factors in addition to storage age may affect the formation of nonfluid milk types of flavors in SMP and additional research is warranted. 
Other dried dairy ingredients were differentiated using the identified language (Fig. 3, 4, Table 6). These products were all dairy ingredients derived in some form from fluid milk so we might expect to see the same basic groups of flavors. Differences in processing and composition provide some of the different types of flavors. Certain flavors are present or are more common in these products than in SMP. For example, milkfat, and fried, fatty/painty flavors were not detected in SMP, but were observed in WMP. These flavors are milkfat-derived flavors. WMP when rehydrated contain $3.5-4.5 \%$ fat (w/w) as opposed to $5 \mathrm{MP}$ which contain less than $0.5 \%$ fat (w/w) so it is expected that fatty flavors would be more prevalent in WMP.

Fishy flavor was not detected in the WMP's evaluated, but was detected in one of the eleven WMP that was evaluated during initial language identification. This WMP was evaluated and discussed by the panel during subsequent training and language refinement. The panel determined that fishy was a distinct and separate flavor, however, that flavor does not appear to be commonly observed in WMP. Heat treatment for WMP is slightly higher than the heat treatment for SMP (Vain= and Sutherland 1996). Cooked and associated flavors such as caramelized flavor can be perceived at higher intensities in WMP.

The whey protein concentrates (WPC) and caseinates exhibited flavors found in SMP but intensities were different. Animal/wetdog flavors and astringency intensities were higher in WPC and caseinates than in SMP $(P<0.05)$ (Fig. 3, 4). A "glue-like" flavor has been reported in caseins and caseinates (Ramshaw and Dunstone 1969). It is possible that the glue-like flavor previously reported is the flavor referred to in this study as animal/wet dog since mucilage and gelatin are also used as descriptors of this flavor concept (Table 2). The compound o-aminoacetophenone (o-AAP) was isolated as a possible contributor of "glue-like" flavor (Rarnshaw and Dunstone 1969). The compound was also identified as an off-flavor 
compound in micromilled milk powder (Preininger and UIlrich 2001) and a prevalent component of stored milk powders (Karagul-Yuceer et al. 2002a). More recent research with caseinates indicates that a combination of other volatile compounds including hexanoic acid, indole, guiacol, and p-cresol may be responsible for the prevalent animal/wet dog flavor (Karagul-Yuceer er al. 2002b). Metallic and cardboard flavors were also prevalent in WPC and caseinates. [Table 4] [Figure 1] [Figure 2] [Table 5] [Table 6] [Table 7] [Table 8] [Figure 3] [Figure 4]

CONCLUSIONS

A defined and referenced language was identified for SMP and other dried dairy ingredients. Several flavors were common to all dried dairy products while others were more prevalent in specific dried dairy ingredients. The standardized descriptive language will provide a useful tool for research, quality control and marketing.

\section{ACKNOWLEDGMENTS}

Funding was provided by the California Dairy Research Foundation. We thank the companies who generously provided samples for this study and for their interest.

\section{REFERENCES}

ADPI. 1998. Ingredient Description Brochure. American Dairy Products Institute, Chicago, IL. ADPI. 2000. Dry milk products utilization \& production trends. American Dairy Products Institute, Chicago, IL.

ADPI. 2001. Standards for grades of dry milks including methods of analysis. American Dairy Products Institute, Chicago. IL. 
BODYFELT, F.W., TOBIAS, J. and TROUT, G. M. 1988. Sensory evaluation of cheese, Ch. 8. In The Sensory Evaluation of Dairy Products, pp. 300-376, AVINan Nostrand Reinhold, New York.

BOM FROST, M., DLIKSTERHUIS, G ,B, and MARTENS, M. 2001. Sensory perception of fat in milk, Food Qual. Pref. 12, 327-336.

CHAPMAN. K.W., LAWLESS, If .T. and BOOR, K.J. 2001. Quantitative descriptive analysis and principal component analysis for sensory characterization of ultrapasteurized milk. J. Dairy Sci. 84, 12-20,

CIVILLE, G.V. and LAWLESS, H. 1986. The Importance of Language in Describing Perceptions. J. Sensory Studies I, 203-215.

DRAKE, M.A. and CIVILLE, G.V. 2003, Flavor lexicons. Compr. Rev. Food Sci. 2, 33-40.

DRAKE, M.A., MCINGVALE, S.C., GERARD, P.D., CADWALLADER, K.R. and CIVILLE, G.V. 2001. Development of a descriptive language for Cheddar cheese. J. Food Sci. 66, $1422-1427$.

DRISCOLL, N.R., BRENNAND, C.P. and HENDRICKS, D.G. 1985. Sensory quality of nonfat dry milk after long-term storage. I. Dairy Sci, 68, 1931-1935.

DRYER, J. 1999. Powder purveyors in the brave new world. Dairy Foods. Jan, 35.

HARRIS, G. 2000. NZMP, New Zealand Milk Products, Personal communication.

HEISSERER, D.M. and CHAMBERS, E. 1993. Determination of the sensory

flavor attributes of aged natural cheese. J. Sensory Studies 8, 121-132. IDF. 1997. Sensory

Evaluation of Dairy Products by Scoring-Reference

Method. International IDF Standard 99C. 
ISHII, R. and O'MAHONEY, M. 1991. Use of multiple standards to define sensory characteristics for descriptive analysis: aspects of concept formation. J. Food Sci. 56, 838842.

KARAGUL-YUCEER, Y., DRAKE, M.A. and CADWALLADER, K.R. 2001. Aroma active components of nonfat dried milk. J. Agric, Food Chem, 49, 2948-2953.

KARAGUL-YUCEER, Y., CADWALLADER, K.R. and DRAKE, M.A. 2002a. Identification of volatile components of stored nonfat dried milk. J. Agric. Food Chem. 50, 305-312.

KARAGUL-YUCEER, Y., VLAHOVICH. K.L., CADWALLADER, K.R. and DRAKE, M.A. 2002b. Compounds responsible for the musky odor of rennet casein. IFT Annual Meeting, June 1519, Anaheim, CA, Abstract 15B-12.

KURTZ, F.E,, TAMSMA, A. and PALLANSCH, M.J. 1971. Organoleptic properties of foam spray-dried products made from deodorized milk fat and skim milk. J. Dairy Sci. 54, 173177.

LAGRANGE, V. 1998. International markets for milk powders. First Annual Concentrated and Dried Milk and Whey Products Symposium. March 30-31, San Francisco, CA.

LAGRANGE, V. 2001. Products containing dairy ingredients — international observations. Third Symposium on Advances in Dairy Product Technology. Feb 27-28, Shell Beach, CA. LAWLESS, H.T. and CLAASSEN, M.R. 1993. Validity of descriptive and defect-oriented terminology systems for sensory analysis of fluid milk. J. Food Sci. 58, 108-112, 119.

LOTONG, V., CHAMBERS, E. and CHAMBERS, D. 2000. Determination of the sensory attributes of wheat sourdough bread. J. Sensory Studies 15, 309-326.

MEILGAARD, M., CIVILLE, G.V. and CARR, B.T. 1999. Sensory Evaluation Techniques, 3'd Ed., CRC Press, Boca Raton, FL. 
MURRAY, J.M. and DELAHUNTY, C.M. 2000. Selection of standards to reference terms in a Cheddar-type cheese flavour language. J. Sensory Studies 15, 179-199.

PREININGER, M. and ULLRICH, F. 2001. Trace compound analysis for off-flavor characterization of micrornilled milk powder. In Gas Chromatography-04factometry - The State of the Art, (J.V. Leland, P. Schieberle, A. Buettner and T.E. Acree, eds.) pp. 46-61, ACS Symposium Series 782, American Chemical Society, Washington, DC.

PRINDIVILLE, E.A., MARSHALL, R.T. and HEYMANN, H. 1999. Effect of milk fat on the sensory properties of chocolate ice cream. J. Dairy Sci. 82, 1425-1432.

PRINDIVILLE, E.A., MARSHALL, R.T. and HEYMANN, H. 2000. Effect of milk fat, cocoa butter, and whey protein fat repiacers on the sensory properties of lowfat and nonfat chocolate ice cream. J. Dairy Sci. 83, 2216-2223.

RAMSHAW, E.H. and DUNSTONE, E.A. 1969. Volatile compounds associated with the off-flavor in stored casein. J. Dairy Res. 36, 215-223. SAS® User's Guide: Statistics, Version 8. 1999. SAS Inst., Cary, NC.

VARNAM, A.H. and SUTHERLAND, J.P. 1996. Milk and Milk Products, pp. 103-158, Chapman \& Hall, London.

WATSON, M.P. and MCEWAN, J.A. 1995. Sensory changes in liquid milk during storage and the effect on consumer acceptance. J. Soc. Dairy Technol. 48, 1-8. 


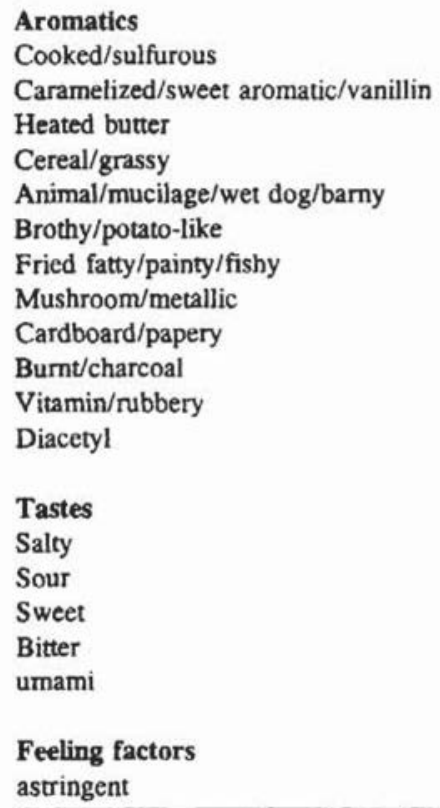

TABLE I. INITIAL MILK POWDER AND DRIED DAIRY

INGREDIENTS LANGUAGE. 


\begin{tabular}{|c|c|c|}
\hline Descriptor & Reference & Preparation \\
\hline Cooked/sulfurous & - Heated milk & $\begin{array}{l}\text { - heat pasteurized skim milk to } 85 \mathrm{C} \text { for } \\
45 \mathrm{~min}\end{array}$ \\
\hline Caramelized/butterscotch & $\begin{array}{l}\text { - Autoclaved milk } \\
\text { - Caramel syrup }\end{array}$ & $\begin{array}{l}\text { - Autoclave whole milk at } 121 \mathrm{C} \text { for } 30 \\
\text { min } \\
\text { - Dilute a tablespoon of caramel syrup } \\
\text { in } 400 \mathrm{~mL} \text { skim milk }\end{array}$ \\
\hline Sweet aromatic/cake mix & $\begin{array}{l}\text { - Pillsbury-White cake mix } \\
\text { - vanillin }\end{array}$ & - dilute $5 \mathrm{mg}$ of vanillin in skim milk \\
\hline Cereal/grass-like & $\begin{array}{l}\text { - breakfast cereals (corn flakes, oat } \\
\text { and wheaties) }\end{array}$ & $\begin{array}{l}\text { soak one cup cereal into three cups } \\
\text { milk for } 30 \text { min and filter to remove } \\
\text { cereals }\end{array}$ \\
\hline Barny & - p-cresol & 20 ppm in skim milk \\
\hline Brothy/potato-like & $\begin{array}{l}\text { - Kroger-Canned white potato slices } \\
\text { - methional }\end{array}$ & $\begin{array}{l}\text { - remove the sliced potatoes from the } \\
\text { broth } \\
\text { - few drops of } 20 \mathrm{ppm} \text { methional in } \\
\text { methanol in sniffing jars }\end{array}$ \\
\hline Animal/gelatin-like/wet dog & - Knox-unflavored gelatin & $\begin{array}{l}\text { dissolve one bag of gelatin }(28 \mathrm{~g}) \text { in } \\
\text { two cups of distilled water }\end{array}$ \\
\hline Milkfat/lactone & $\begin{array}{l}\text { Heavy cream } \\
\text { delta dodecalactone }\end{array}$ & $40 \mathrm{ppm}$ on filter paper \\
\hline Fried fatty/painty & - (E,E)-2,4-decadienal & $-2 \mathrm{ppb}$ in skim milk \\
\hline Fishy & $\begin{array}{l}\text { Fresh fish with skin } \\
\text { Canned tuna juice }\end{array}$ & \\
\hline Mushroom/metallic & - fresh mushroom & $\begin{array}{l}\text { - slice fresh mushroom in skim milk for } \\
30 \mathrm{~min} \text { and filter to remove mush- } \\
\text { room slices }\end{array}$ \\
\hline Papery/cardboard & - cardboard paper & $\begin{array}{l}\text { - soak pieces of cardboard paper in } \\
\text { skim milk overnight }\end{array}$ \\
\hline Bume/charcoal & - over toasted bread slice & \\
\hline Vitamin/rubber & - Enfamil - liquid Polyvisol vitamins & \\
\hline Diacetyl & diacetyl & Diacetyl, $20 \mathrm{ppm}$ on filter paper \\
\hline Earthy/musty & $\begin{array}{l}\text { potting soil, odor reminiscent of damp } \\
\text { basement }\end{array}$ & \\
\hline Sweet taste & - sucrose & - $5 \%$ sucrose solution \\
\hline Salty & $-\mathrm{NaCl}$ & $-2 \% \mathrm{NaCl}$ solution \\
\hline Sour & - citric acid & - $1 \%$ citric acid solution \\
\hline Bitter & - caffeine & $-0.5 \%$ caffeine solution \\
\hline Umami & monosodium glutamate & $-1 \%$ MSG in water \\
\hline Astringent & - tea & - soak 6 tea bags in water for $10 \mathrm{~min}$ \\
\hline
\end{tabular}

TABLE 2. REFINED LANGUAGE AND PREPARATION OF

REFERENCE MATERIALS. 


\begin{tabular}{|c|c|c|c|c|}
\hline Sample & Source & Heat Treatment & Storage & Áge \\
\hline 1. SMP & International & low & 2-ply bag & $>3 \mathrm{mo}$ \\
\hline 2. SMP & U.S. (local store) & low & paperboard & unknown \\
\hline 3. SMP & International & low & 2-ply bag & $>3 \mathrm{mo}$ \\
\hline 4. SMP & U.S. & low & 2-ply bag & $>3 \mathrm{mo}$ \\
\hline 5. SMP & International & low & 2-ply bag & $>3 \mathrm{mo}$ \\
\hline 6. fluid skim & U.S. (local store) & $\mathrm{n} / \mathrm{a}$ & yellow jug & $\mathrm{n} / \mathrm{a}$ \\
\hline 7. SMP & U.S. & low & 2-ply bag & $>3 \mathrm{mo}$ \\
\hline 8. SMP & U.S. & low & 2-ply bag & $>3 \mathrm{mo}$ \\
\hline 9. SMP & U.S. & low & 2-ply bag & $>3 \mathrm{mo}$ \\
\hline 10. SMP & U.S. & high & 2-ply bag & $>3 \mathrm{mo}$ \\
\hline 11. SMP & International & low & 2-ply bag & $>3 \mathrm{mo}$ \\
\hline 12. SMP & International & low & 2-ply bag & $>3 \mathrm{mo}$ \\
\hline 13. SMP & U.S. & low & 2-ply bag & $6 \mathrm{mo}$ \\
\hline 14. SMP & U.S. & low & can & $20 \mathrm{yr}$ \\
\hline 15. SMP & U.S. & medium & 2-ply bag & $6 \mathrm{mo}$ \\
\hline 16. SMP & U.S. & low & 2-ply bag & $6 \mathrm{mo}$ \\
\hline 17. SMP & International & low & 2-ply bag & $>3 \mathrm{mo}$ \\
\hline 18. SMP & U.S. (local store) & low & paperboard & $3 \mathrm{yr}$ \\
\hline 19. SMP & International & low & 2-ply bag & $6 \mathrm{mo}$ \\
\hline 20. SMP & International & low & 2-ply bag & $8 \mathrm{mo}$ \\
\hline 21. SMP & U.S. & low & 2-ply bag & $>3 \mathrm{mo}$ \\
\hline 22. SMP & International & low & 2-ply bag & $>3 \mathrm{mo}$ \\
\hline 23. SMP & International & high & 2-ply bag & $>3 \mathrm{mo}$ \\
\hline 24. SMP & U.S. & med & 2-ply bag & $>3 \mathrm{mo}$ \\
\hline 25. SMP & U.S. & high & 2-ply bag & $>3 \mathrm{mo}$ \\
\hline 26. SMP & U.S. & high & 2-ply bag & $>3 \mathrm{mo}$ \\
\hline 27. SMP & U.S. & low & 2-ply bag & $>3 \mathrm{mo}$ \\
\hline 28. WMP & U.S. & $\mathrm{n} / \mathrm{a}$ & 2-ply bag & $>3 \mathrm{mo}$ \\
\hline 29. WMP & U.S. & $\mathrm{n} / \mathrm{a}$ & 2-ply bag & $>3 \mathrm{mo}$ \\
\hline 30. WMP & International & $\mathrm{n} / \mathrm{a}$ & 2-ply bag & $>3 \mathrm{mo}$ \\
\hline 31. Evaporated milk & U.S. (local store) & $\mathrm{n} / \mathrm{a}$ & can & unknown \\
\hline 32. Caseinate & U.S. & $n / a$ & 2-ply bag & $>3 \mathrm{mo}$ \\
\hline 33. Caseinate & International & $\mathrm{n} / \mathrm{a}$ & 2-ply bag & $>3 \mathrm{mo}$ \\
\hline 34. WPC34 & U.S. & $\mathrm{n} / \mathrm{a}$ & plastic can ${ }^{2}$ & $>3 \mathrm{mo}$ \\
\hline 35. WPC34 & U.S. & $\mathrm{n} / \mathrm{a}$ & plastic can ${ }^{2}$ & $>3 \mathrm{mo}$ \\
\hline 36. WPC34 & U.S. & $\mathrm{n} / \mathrm{a}$ & plastic can ${ }^{2}$ & $>3 \mathrm{mo}$ \\
\hline 37. WPC 80 & U.S. & $\mathrm{n} / \mathrm{a}$ & plastic can ${ }^{2}$ & $>3 \mathrm{mo}$ \\
\hline
\end{tabular}

sample received in plastic bag within a sealed plastic canister

TABLE 3. SAMPLES EVALUATED USING THE

DEVELOPED LANGUAGE. 


\begin{tabular}{|l|l|l|l|l|l|l|l|l|l|}
\hline sample & cooked & Swtarom & cereal & An/wd & pot & crdbrd & sweet & salty & astrgt \\
\hline 1 & 2.7 & 0.9 & 0.8 & 3.4 & 3.0 & 0.5 & 1.0 & 0.3 & 2.1 \\
\hline 2 & 2.8 & 2.0 & 1.0 & 0.9 & 1.3 & 1.5 & 2.5 & 0.3 & 2.0 \\
\hline 3 & 2.8 & 2.2 & 1.0 & 0.9 & 1.3 & 1.5 & 2.6 & 0.2 & 1.9 \\
\hline 4 & 3.1 & 1.3 & 0.8 & 2.5 & 3.0 & 1.0 & 2.1 & 0.3 & 2.4 \\
\hline 5 & 3.0 & 1.9 & 1.0 & 2.2 & 1.1 & 2.0 & 2.1 & 0.2 & 2.1 \\
\hline 6 & 2.3 & 1.6 & 1.0 & 0.0 & 0.0 & 0.4 & 2.2 & 0.3 & 1.5 \\
\hline 7 & 2.8 & 2.0 & 1.2 & 0.8 & 1.5 & 1.6 & 2.1 & 0.3 & 2.0 \\
\hline 8 & 3.1 & 1.9 & 1.0 & 0.8 & 2.0 & 1.4 & 2.2 & 0.3 & 2.0 \\
\hline 9 & 2.7 & 2.1 & 1.3 & 0.5 & 1.7 & 1.6 & 2.6 & 0.3 & 1.5 \\
\hline 10 & 2.9 & 1.6 & 1.3 & 1.2 & 2.3 & 1.3 & 2.2 & 0.3 & 2.1 \\
\hline 11 & 2.8 & 1.4 & 1.8 & 1.4 & 2.1 & 11 & 2.0 & 1.1 & 2.0 \\
\hline 12 & 2.7 & 1.2 & 1.0 & 3.0 & 2.6 & 0.6 & 1.8 & 0.3 & 1.9 \\
\hline 13 & 2.8 & 1.9 & 1.3 & 0.7 & 2.0 & 2.0 & 2.1 & 0.3 & 2.1 \\
\hline 14 & 2.9 & 1.3 & 1.8 & 0.3 & 2.5 & 1.0 & 1.4 & 2.3 & 2.8 \\
\hline 15 & 3.0 & 1.5 & 1.3 & 1.4 & 2.3 & 1.9 & 2.1 & 0.3 & 2.1 \\
\hline 16 & 2.8 & 2.2 & 1.7 & 0.5 & 1.5 & 1.9 & 2.3 & 0.3 & 2.4 \\
\hline 17 & 2.9 & 1.6 & 1.0 & 0.7 & 1.7 & 1.5 & 2.0 & 0.2 & 2.0 \\
\hline 18 & 2.6 & 0.4 & 0.4 & 0.3 & 0.0 & 0.6 & 1.0 & 0.2 & 3.1 \\
\hline 19 & 2.7 & 1.3 & 1.4 & 1.4 & 1.7 & 1.0 & 2.4 & 0.3 & 1.5 \\
\hline 20 & 2.8 & 1.4 & 1.4 & 0.3 & 1.0 & 0.5 & 2.4 & 0.3 & 1.9 \\
\hline 21 & 2.9 & 1.4 & 1.0 & 0.7 & 2.1 & 0.4 & 2.3 & 0.2 & 2.0 \\
\hline 22 & 2.5 & 0.8 & 1.0 & 2.4 & 2.6 & 1.0 & 1.5 & 0.2 & 2.1 \\
\hline 23 & 2.7 & 1.0 & 1.5 & 0.8 & 2.0 & 1.8 & 2.1 & 0.2 & 2.1 \\
\hline 24 & 2.5 & 0.8 & 1.8 & 0.3 & 1.5 & 1.0 & 2.3 & 0.4 & 1.5 \\
\hline 25 & 3.2 & 0.8 & 1.0 & 2.1 & 1.5 & 0.5 & 1.1 & 0.8 & 2.2 \\
\hline 26 & 3.0 & 1.0 & 0.5 & 1.1 & 0.5 & 1.8 & 1.0 & 0.4 & 2.1 \\
\hline 27 & 2.0 & 3.2 & 0.0 & 0.0 & 0.0 & 0.0 & 2.5 & 0.3 & 1.0 \\
\hline LSD & 0.3 & 0.3 & 0.3 & 0.4 & 0.4 & 0.3 & 0.3 & 0.3 & 0.3 \\
\hline
\end{tabular}

' flavor intensities observed in three or more skim milk powders

Cooked - cooked flavor, swtarom - sweet aromatic, cereal - cereal, an/wd - animal/wet dog, pot - potato/brothy, crdbrd - cardboard, sweet - sweet taste, salty - salty taste, astrgt - astringent. For complete references, see Table 2.

TABLE 4. INTENSITY SCORES FOR FREQUENTLY

OBSERVED FLAVOR ATTRIBUTES' OF SKIM MILK

POWDERS 


\begin{tabular}{|l|l|}
\hline Attribute & Sample and Intensity \\
\hline Caramelized & SMP 10 $=1.8$, SMP 14 =2.2 \\
\hline Burnt & SMP 23 $=1.4$ \\
\hline Animal/Barny & SMP 20 $=2.2$ \\
\hline Vitamin/rubbery & SMP 18 $=3.9$ \\
\hline Free fatty acid & SMP 14 $=1.0$ \\
\hline Earthy/musty & SMP 14 $=1.1$ \\
\hline Bitter & SMP 23 $=1.4$ \\
\hline Sour & SMP 14 $=2.2$ \\
\hline
\end{tabular}

TABLE 5. ATTRIBUTES AND INTENSITY SCORES

FOUND IN TWO OR FEWER SKIM MILK POWDERS

\begin{tabular}{|l|l|}
\hline Attribute & Sample and Intensity \\
\hline diacetyl & WPC34 $=1.0$ \\
\hline Cereal/grass-like & WMP28 $=2.1$ \\
\hline umami & WPC34 $=1.5$ \\
\hline
\end{tabular}

' Whey protein concentrate (WPC), whole milk powder (WMP), or caseinate

TABLE 6. ATTRIBUTES AND INTENSITY SCORES

FOUND IN FEWER THAN TWO OTHER1 DAIRY

INGREDIENTS

\begin{tabular}{|l|c|c|c|c|}
\hline Attributes & Factor 1 & Factor 2 & Factor 3 & Factor 4 \\
\hline cooked & 0.03 & 0.66 & 0.57 & 0.04 \\
\hline Sweet aromatic & 0.79 & 0.25 & 0.26 & 0.05 \\
\hline cereal & 0.32 & -0.77 & 0.20 & -0.17 \\
\hline Animal/wetdog & -0.80 & 0.28 & 0.13 & -0.11 \\
\hline Potato/brothy & -0.84 & 0.13 & 0.13 & 0.08 \\
\hline cardboard & 0.43 & -0.06 & 0.65 & -0.52 \\
\hline Sweet taste & 0.63 & 0.26 & -0.03 & 0.65 \\
\hline salty & -0.08 & -0.66 & 0.32 & 0.36 \\
\hline astringent & -0.40 & -0.15 & 0.72 & 0.31 \\
\hline \% variance & 31 & 22 & 17 & 12 \\
\hline explained & & & & \\
\hline
\end{tabular}

Numbers in bold are believed to be of primary importance.

TABLE 7. FACTOR LOADINGS FOR SENSORY

ATTRIBUTES OF SKIM MILK POWDERS 


\begin{tabular}{|l|c|c|c|c|c|c|c|c|}
\hline & Swe/aro & cereal & An/wd & Potato & cardbrd & sweet & salty & astrgt \\
\hline Cooked & 0.25 & -0.31 & 0.15 & 0.10 & 0.34 & 0.16 & 0.13 & 0.19 \\
\hline Swe/aro & & 0.08 & $-0.55^{*}$ & $-0.56^{*}$ & 0.35 & $0.51^{*}$ & 0.20 & 0.08 \\
\hline cereal & & & $-0.42^{*}$ & $-0.25^{*}$ & 0.24 & -0.04 & 0.04 & 0.08 \\
\hline An/wd & & & & $0.63^{*}$ & -0.14 & $-0.42^{*}$ & 0.03 & 0.28 \\
\hline Potato & & & & & -0.30 & $-0.40^{*}$ & 0.03 & $0.44^{*}$ \\
\hline Cardbrd & & & & & & 0.03 & 0.02 & 0.10 \\
\hline Sweet & & & & & & & 0.10 & 0.16 \\
\hline Salty & & & & & & & & 0.35 \\
\hline
\end{tabular}

* denotes significant correlation $(P<0.002)$

Cooked - cooked flavor, swe/aro - sweet aromatic, cereal - cereal, an/wd - animal/wet dog, potato - potato/brothy, crdbrd - cardboard, sweet - sweet taste, salty - salty taste, astrgt astringent. For complete references, see Table 2.

TABLE 8. PEARSON CORRELATIONS BETWEEN TERMS

FOR SKIM MILK POWDER EVALUATION.

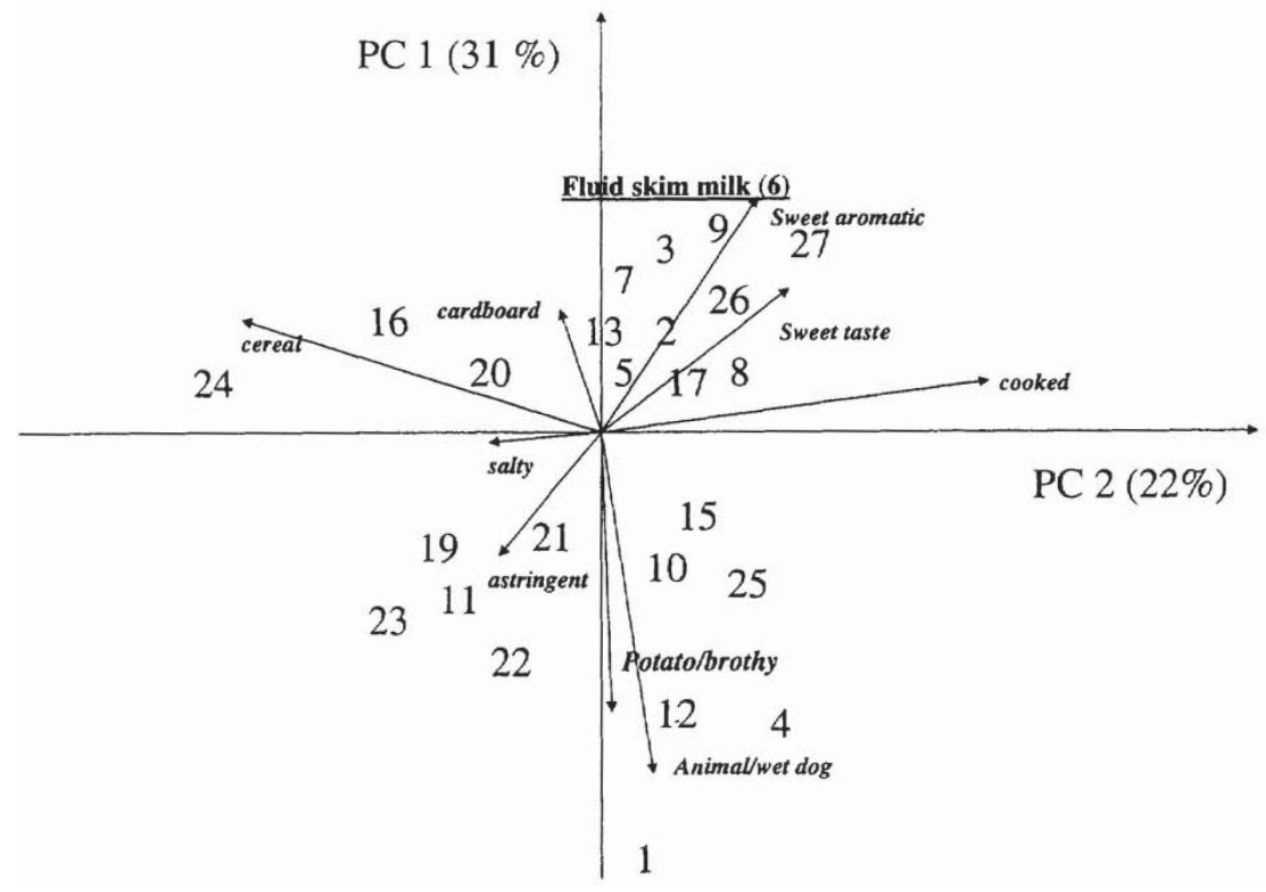

FIG. I. PRJNCIPAL COMPONENT BIPLOT OF SMP AS

SEPARATED BY PCl AND PC2

SMP are represented by numbers (see Table 3). 


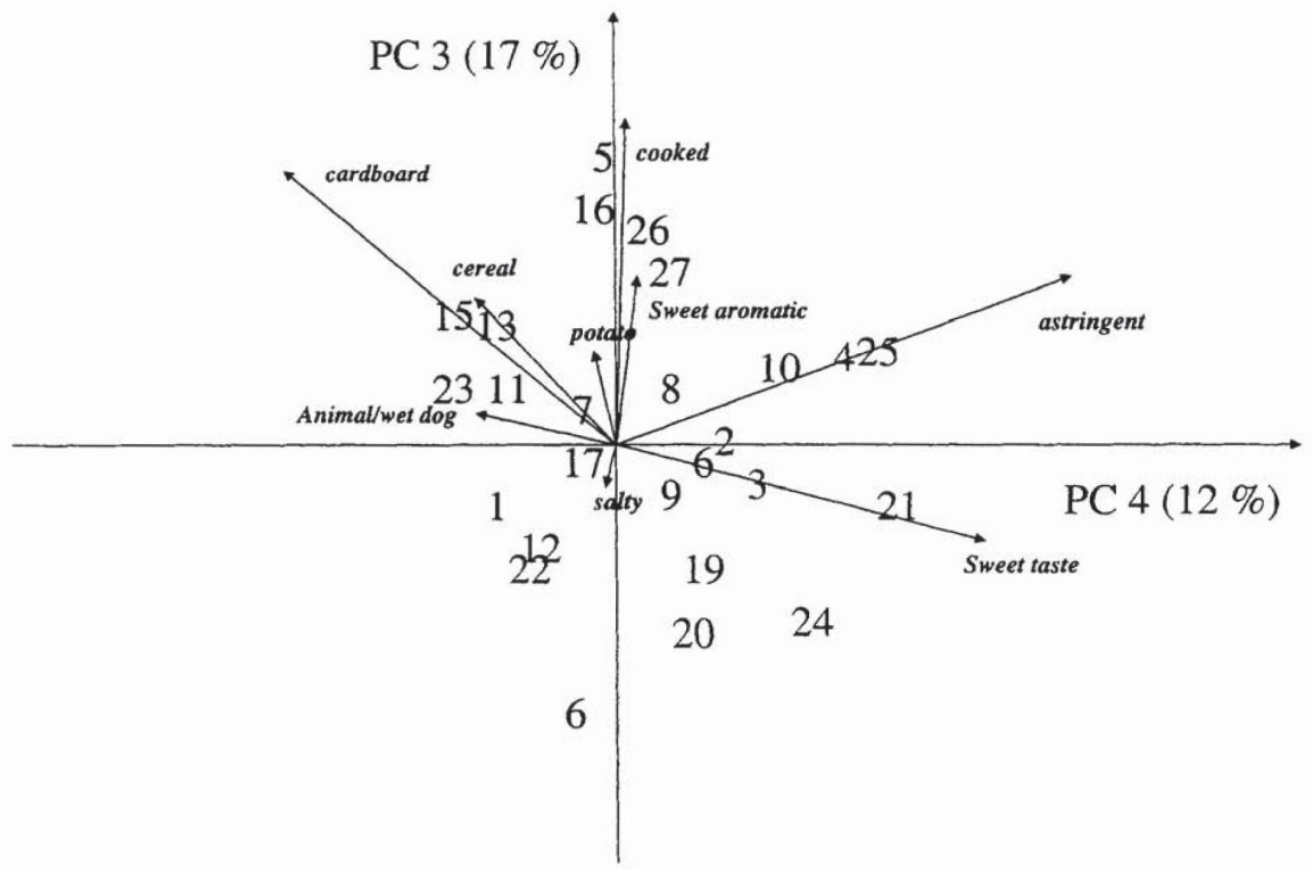

FIG. 2. PRJNCIPAL COMPONENT BIPLOT OF SMP AS

SEPARATED BY PC3 AND PC4

SMP are represented by numbers (see Table 3).

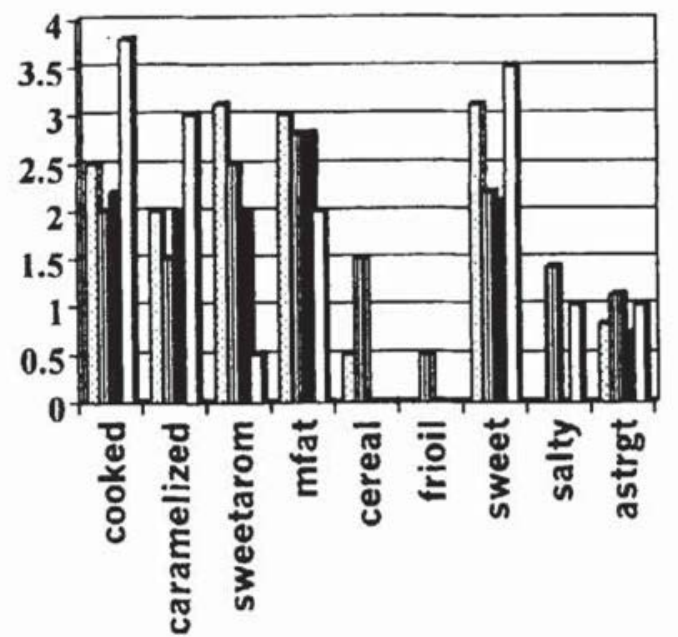

\begin{tabular}{|l|}
\hline WMP27 \\
W WMP28 \\
WMP29 \\
$\square$ Evap
\end{tabular}

FIG. 3. ATIRIBUTES AND INTENSITIES OF WHOLE MILK

POWDERS AND EVAPORATED MILK

Cooked $\bullet$ cooked flavor, caramelized flavor, sweetarom- sweet

aromatic, mfat- milkfat flavor, cereal - cereal, frioil - fried, 
fatty/painty, sweet - sweet taste, salty - salty taste, astrgt-

astringent . For complete references, see Table 2.

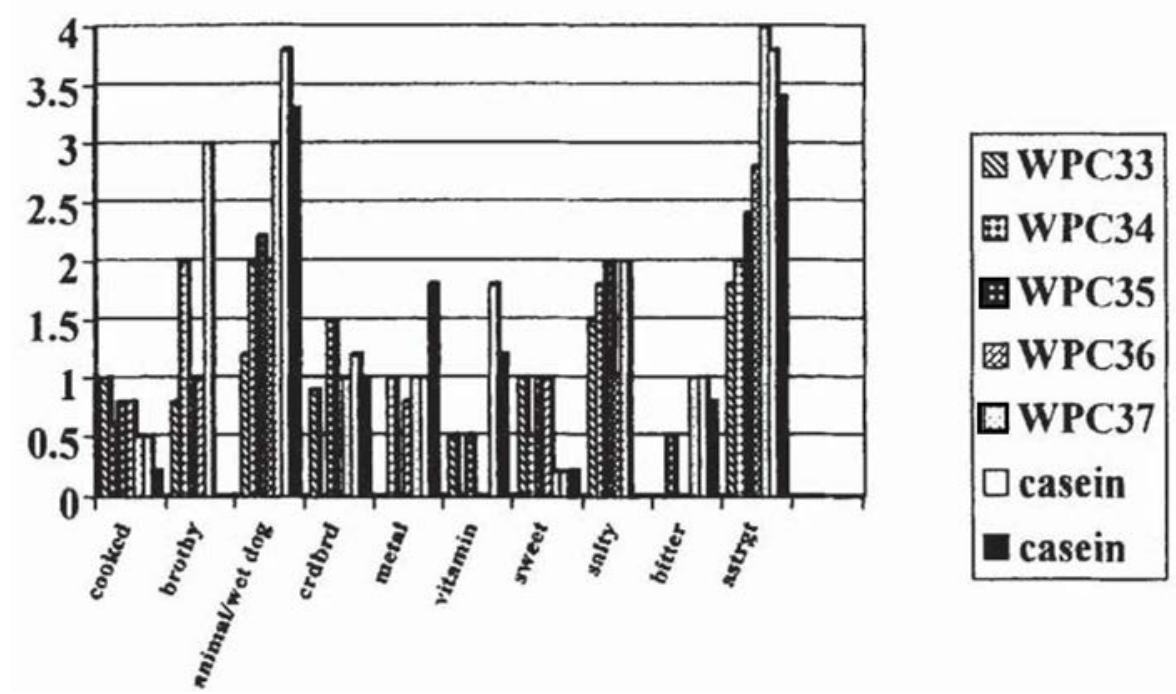

FIG. 4. ATTRIBUTES AND INTENSITIES OF CASEINATES

\section{AND WHEY PROTEIN CONCENTRATES}

Cooked- cooked flavor, animal/wet dog - animal/wet dog, brothy

- potato/brothy. crdbrd - cardboard, metal - mushroom/metallic,

vitamin - vitamin, sweet- sweet taste, salty - salty taste, bitter -

bitter, astringent - astringent. For complete references, see

Table:z. 